\title{
Interdisciplinary Primary Care Team Expertise and Diabetes Care Management
}

\author{
Chris Miller-Rosales, MSPH and Hector P. Rodriguez, PhD, MPH
}

Background: Interdisciplinary primary care team expertise can aid patient self management of type 2 diabetes, but small community health centers (CHCs) may not have the volume to consistently provide interprofessional care. We examine whether care team role expertise is associated with patients' experiences of chronic care and whether the relationship is stronger for small CHC sites.

Methods: Surveys of 1277 adults with diabetes $(2012$; response rate $=47 \%)$ that assessed nonphysician team roles involved in managing their chronic care, including community health workers, diabetes educators, nutritionists, pharmacists, mental health providers, and other general staff, were integrated with clinical and administrative data from 14 CHCs. Random effects regression models estimated the association of team expertise, CHC size, and 1) patients' experiences of chronic care; and 2) hemoglobin A1c control, controlling for patient comorbidities, sex, race/ethnicity/primary language, age, and insurance coverage.

Results: Care teams with community health workers $(\beta=7.67, P<.01)$, diabetes educators $(\beta=6.05, P<.01)$, nutritionists $(\beta=5.21, P<.01)$, and other general staff $(\beta=4.96, P=.02)$ were associated with better patients' experiences of chronic care, but not hemoglobin A1c control. Patients of small CHC sites reported better experiences of care $(\beta=2.15, P=.03)$ with each additional team role reported, but the relationship was not significant for large CHCs.

Conclusions: Patients with access to care team expertise in self-management support, including diabetes educators, nutritionists, community health workers, and other general staff report better experiences of chronic care. These team roles may reduce barriers to patient self management and improve patients' overall experiences of chronic care, particularly in small CHC sites. ( $\mathrm{J}$ Am Board Fam Med 2021;34:151-161.)

Keywords: Community Health Centers, Community Health Workers, Minority Health, Patient Care Team, Primary Health Care, Self-Management, Type 2 Diabetes Mellitus

\section{Introduction}

Adult patients with type 2 diabetes and other chronic conditions need support to improve their self-management skills, particularly socioeconomically vulnerable populations that face more social and nonmedical barriers to diabetes control. ${ }^{1-3}$ The

This article was externally peer reviewed.

Submitted 4 May 2020; revised 2 August 2020; accepted 6 August 2020.

From the School of Public Health, University of California-Berkeley, Berkeley, CA (CMR, HPR)

Funding: This study was funded by the Agency for Healthcare Research and Quality with grant \#R18HS020120 (PI: HPR). CMR was supported by the UC Berkeley Sutter Health Research Fellowship Program. The contents of the manuscript are solely the responsibility of the authors and do not necessarily represent the official views of Sutter Health.

Conflict of interest: None.

Corresponding author: Chris Miller-Rosales, MSPH, School of Public Health, University of California-Berkeley, 2121 Berkeley Way, Room 5302, Berkeley, CA 94720-7360, (E-mail: cmiller@berkeley.edu). availability of broad, interdisciplinary expertise on primary care teams may improve patient self management by providing different skills in overcoming barriers to self management. Previous research among commercially insured patients indicates that access to nurse practitioner, nurse, and nutritionist expertise on care teams is associated with better self management of diabetes, ${ }^{4}$ but it remains unclear whether the benefits of broader team expertise extend to socioeconomically vulnerable patients receiving care in community health centers (CHCs). The unique organizational context of CHCs, including high turnover and financial instability, ${ }^{5-7}$ may affect patient access to and experience with interdisciplinary care teams.

CHCs are safety net health care organizations with a mission to provide outpatient care to underserved and socioeconomically disadvantaged communities. CHCs have long faced staff shortages, with large vacancies in physicians and registered 
nurses. ${ }^{7}$ Effective interdisciplinary primary care teams are essential for $\mathrm{CHCs}$ because high primary care clinician (PCC) turnover has led many CHCs to assign patients to care teams or sites rather than individual PCCs. ${ }^{8}$ Care team assignment may be less than optimal for fostering PCC-patient relationships because continuous relationships with individual PCCs promotes patient trust and treatment adherence, ${ }^{9-11}$ while care team approaches can be implemented in ways that are not patient-centered. ${ }^{11,12}$

Organizational facilitators of effective care teams may vary depending on $\mathrm{CHC}$ size. Higher-volume facilities may have greater slack resources to hire staff and sufficient health information technology to coordinate patient care compared with smaller volume facilities. However, small CHC sites have the benefit of fostering interpersonal relationships through small size, ${ }^{13}$ and can use interorganizational partnerships to share personnel and resources including data analysts, care coordinators, and nutritionists. ${ }^{14}$ Previous research has demonstrated smaller primary care practices have better access to care and fewer potentially preventable hospital admissions than large primary care practices. ${ }^{15,16}$ If care teams of small CHC sites are more effective in coordinating care because of their relationships, interdisciplinary expertise may improve patient self management and glycated hemoglobin (HbAlc) control, rather than result in process losses due to coordination problems.

We examine the extent to which the availability of interdisciplinary expertise on primary care teams is associated with better diabetic patients' experiences of chronic care and HbAlc control. To examine whether interdisciplinary expertise differs by practice size, we assess whether the relationship between expertise and patient outcomes differ in small versus large $\mathrm{CHC}$ sites. Previous studies have separately found that the expertise of individual care team members $^{17-26}$ and overall team expertise ${ }^{4}$ contribute to effective chronic care management. We build on previous research by including community health workers (CHWs) and diabetes educators as expertise sources central to care management in $\mathrm{CHCs}$, as well as disentangling the effect of specific team expertise from the overall expertise on the primary care team.

\section{Methods}

This study analyzes cross-sectional data collected as part of a cluster-randomized trial of $14 \mathrm{CHC}$ sites in California. ${ }^{27}$ Patients were sampled in 2011 and the survey was fielded in 2012 (response rate = $47 \%$ ). The survey was mailed to a random sample of patients who were least 18 years old, had at least 2 visits to a participating $\mathrm{CHC}$ site, and had a type 2 diabetes diagnosis code or prescription per the SUPREME-DM definition. ${ }^{28}$ A 2-visit criterion was used to assess the perspectives of established patients of the CHCs. The survey was fielded in English, Spanish, and Chinese, and included a \$10 gift card. Nonrespondents were contacted by phone for up to 8 attempts, patients were given the option to consent and complete the survey over phone. From 1396 total respondents, 119 patients (8.5\%) were excluded due to incomplete survey responses, resulting in an analytic sample of 1277 patient surveys, which were linked with 2011 to 2012 clinical and administrative data.

\section{Outcome Variables}

The 2 study outcomes are 1) patients' experiences of chronic care, and 2) HbA1c control. Patients' experiences of chronic care were assessed using a diabetesspecific adaptation of the Patient Assessment of Chronic Illness Care (PACIC-11). ${ }^{29,30}$ Questions included: "Over the past 6 months, when I received care for my diabetes at this clinic, how often was I: given choices about treatments to think about; helped to set specific goals to improve my eating or exercise; and helped to plan ahead so I could take care of my condition even in hard times." Response categories included "never," "sometimes," "usually," and "always." To generate a composite, responses to PACIC-11 questions were scored as a continuous measure (range, 0 to 100; internal consistency reliability, $\alpha=0.91$ ). Following the half-scale rule, a composite score was only calculated for patients with at least half of the questions completed. ${ }^{31}$

We measured HbAlc through a dichotomous measure coded as 1 for acceptable control (HbAlc result $<8.0 \%$ ) versus 0 for poor control. ${ }^{32}$ This is consistent with the American Diabetes Association's guideline as a reasonable HbA1c goal for patients with comorbid conditions. ${ }^{33}$

\section{Independent Variables}

Our main independent variables are 1) access to specific team expertise, and 2) an overall count of interdisciplinary expertise on the primary care team. Access to team expertise was assessed using patient reports of CHC clinicians and staff endorsed as "help[ing] you with your diabetes," 
including community health workers, diabetes educators, nutritionists, pharmacists, mental health providers, and other general staff. Overall care team expertise is a count of the number of team expertise sources reported, ranging from 0 (none) to 6. Both expertise measures are measured at the patient level given that patients have different constellations of clinicians involved in their diabetes care based on their needs and preferences.

CHC site size was examined as a moderator of the team expertise and diabetes care management relationship and was measured by the annual (2012) unique adults with diabetes the site served. CHC sites served a range from 118 to 1609 adult patients with diabetes. Sites were classified as large $(n=6)$ if they cared for 250 or more adults with diabetes or small $(n=8)$ if they cared for fewer than 250 adults with diabetes.

Patient sex, age, insurance, and comorbidity information was sourced from administrative and clinical data. Race, ethnicity, primary language information, and how long the patient was established with the $\mathrm{CHC}$ site $(<3$ years, 3 to 5 years, $5+$ years) were collected in the patient survey. We constructed a combined categorical variable for race, ethnicity, and language given their correlation in the patient responses: ${ }^{34}$ Asian patients speaking Chinese ( $\mathrm{n}=578)$, Asian patients speaking English $(\mathrm{n}=116)$, Latino patients speaking Spanish $(\mathrm{n}=$ 132), Latino patients speaking English $(n=166)$, and English-speaking patients of other racial/ethnic background $(n=404)$, including Black and nonLatino White patients.

\section{Statistical Analysis}

Descriptive statistics compare patient characteristics and predictor variables in small versus large CHC sites; t-tests were used for continuous variables and Chi-square tests for categorical variables. Multivariable logistic regression estimated the association of patient access to specific team expertise, overall care team expertise, and $\mathrm{CHC}$ site size (small vs large) on HbA1c control $(<8.0 \%)$. To examine whether patients of small CHC sites benefit more from expertise, we tested an interaction between site size and overall interdisciplinary expertise. Then, multivariable linear regression models estimated the association of patient access to specific team expertise, overall care team expertise, and CHC site size (small vs large) on patients' experiences of chronic care (PACIC-11). An interaction between site size and overall interdisciplinary expertise was included to assess whether patients of small CHC sites benefit more from expertise. Models included random $\mathrm{CHC}$ site effects to account for the clustering of patients within $\mathrm{CHC}$ sites, and control for patient age, sex, race/ethnicity/language, insurance source, and comorbidities.

We used Little's test to assess covariate-dependent missingness, ${ }^{35}$ then multiple imputation was conducted for missing values. We computed the Variance Inflation Factor (VIF) for all independent variables and used a cutoff of $\mathrm{VIF} \geq 2$ to assess potential collinearity. To examine the robustness of the $\mathrm{HbAlc}$ result, we estimated a logistic regression with an $\mathrm{HbA1c}$ cut point of $\leq 9.0 \%$ designated as acceptable control, as well as a linear regression model using a continuous measure of HbA1c. More clinically complex patients may have greater need for team expertise. To assess the sensitivity of our findings to potential selection effects, inverse probability of treatment weights (IPTWs) were used for each patient. IPTWs were calculated equal to the inverse of the probability of having access to any non-PCC expertise, conditional on control variables. All statistical analyses were completed using STATA 16.0 (StataCorp, College Station, TX) by the authors and approved by the Institutional Review Board of the University of California-Berkeley.

\section{Results}

Distribution of patient characteristics are comparable in small and large $\mathrm{CHC}$ sites, except for patient sex $(P<.05)$ and race/ethnicity/language $(P<.001)$ (Table 1). Small CHC sites had a lower percentage of female patients compared with large $\mathrm{CHC}$ sites (overall: $57.6 \%$, small sites: $54.1 \%$, large sites: $59.8 \%$ ). The most common category of race/ethnicity/language are Chinese-speaking Asian patients (overall: $40.3 \%$, small sites: $30.4 \%$, large sites: $47.5 \%)$, followed by Spanish-speaking Latino patients (overall: $29.4 \%$, small sites: $38.8 \%$, large sites: $23.6 \%$ ), English-speaking Latino patients (overall: $12.5 \%$, small sites: $13.8 \%$, large sites: $11.6 \%)$, English-speaking patients of other racial/ ethnic backgrounds (overall: 9.5\%, small sites: 7.6\%, large sites: 10.6\%), and English-Speaking Asian patients (overall: $8.5 \%$, small sites: 9.3\%, large sites: $7.9 \%$ ). Mean number of comorbid conditions is 2.99 (standard error $=1.9$ ) and more than half of patients are between 46 and 65 years old 
Table 1. Adult Diabetic Patient Characteristics for the Overall Sample and Compared between Small and Large Community Health Center (CHC) Sites, 2011-2012

\begin{tabular}{|c|c|c|c|c|}
\hline $\begin{array}{l}\text { Variable } \\
\text { Percentage of Population, Mean (Standard Error) }\end{array}$ & Overall & Small CHC Site & Large CHC Site & $P$-Value \\
\hline Female & $57.6 \%$ & $54.1 \%$ & $59.8 \%$ & $.048^{*}$ \\
\hline Age (years old) & & & & .36 \\
\hline 26 to 35 & $3.0 \%$ & $2.1 \%$ & $3.5 \%$ & \\
\hline 36 to 45 & $10.1 \%$ & $11.8 \%$ & $9.1 \%$ & \\
\hline 46 to 55 & $23.8 \%$ & $22.9 \%$ & $24.3 \%$ & \\
\hline 56 to 65 & $35.5 \%$ & $36.4 \%$ & $34.9 \%$ & \\
\hline 66 to 75 & $19.3 \%$ & $19.4 \%$ & $19.3 \%$ & \\
\hline $76+$ & $8.3 \%$ & $7.4 \%$ & $8.8 \%$ & \\
\hline Race/ethnicity/language & & & & $<.01^{*}$ \\
\hline Chinese-speaking Asian & $40.3 \%$ & $30.4 \%$ & $46.3 \%$ & \\
\hline English-speaking Asian & $8.5 \%$ & $9.3 \%$ & $7.9 \%$ & \\
\hline English-speaking Latino & $12.5 \%$ & $13.8 \%$ & $11.6 \%$ & \\
\hline Spanish-speaking Latino & $29.4 \%$ & $38.8 \%$ & $23.6 \%$ & \\
\hline English-speaking other & $9.5 \%$ & $7.6 \%$ & $10.6 \%$ & \\
\hline Insurance source & & & & .20 \\
\hline Medicaid & $33.0 \%$ & $36.9 \%$ & $30.7 \%$ & \\
\hline Medicare & $5.4 \%$ & $6.0 \%$ & $5.0 \%$ & \\
\hline Other & $2.8 \%$ & $2.8 \%$ & $2.8 \%$ & \\
\hline Private & $27.9 \%$ & $26.0 \%$ & $29.0 \%$ & \\
\hline Uninsured & $31.0 \%$ & $28.3 \%$ & $32.5 \%$ & \\
\hline Total comorbidities & $2.9(1.9)$ & $3.0(1.9)$ & $2.9(1.9)$ & .56 \\
\hline How long usual clinic & & & & .18 \\
\hline$<3$ years & $32.5 \%$ & $32.4 \%$ & $32.5 \%$ & \\
\hline 3 to 5 years & $28.7 \%$ & $31.4 \%$ & $27.0 \%$ & \\
\hline $5+$ years & $38.9 \%$ & $36.2 \%$ & $40.5 \%$ & \\
\hline Observations & 1277 & 484 & 793 & \\
\hline
\end{tabular}

This comparison of means analyses utilizes $\chi^{2}$ tests for categorical variables and $t$-test for continuous variables to compare patient characteristics in small versus large community health center sites.

${ }^{*} P$-values represent the significance of differences in individual characteristics between small versus large sites.

(58.3\%). Medicaid is the most common insurance coverage $(33.0 \%)$, followed by uninsured $(31.0 \%)$, private insurance (27.9\%), and Medicare (5.4\%).

Interdisciplinary team expertise was similar for both small and large CHC sites (Table 2). The mean number of specific team members available beyond primary care physicians and nurses reported by patients was 0.81 (standard error $=1.31$ ) and this did not differ for small and large CHC sites. Roughly 1 out of 5 patients in both small and large CHC sites report access to the expertise of nutritionists, diabetes educators, pharmacists, and other general staff. There was no significant difference between small and large CHC sites in patient access to specific team expertise except for other general staff, where patients of small CHC sites were more likely to report access to other general staff in their diabetes care $(P=.01)$. Nutritionists were the most common care team member available to patients (overall: $28.4 \%$, small sites: $27.3 \%$, large sites: 29.2\%), followed by general staff (overall: $22.3 \%$, small sites: $25.8 \%$, large sites: $20.1 \%$ ), diabetes educators (overall: 19.3\%, small sites: 19.9\%, large sites: $19.0 \%$ ), pharmacists (overall: $18.2 \%$, small sites: $19.0 \%$, large sites: $17.7 \%$ ), community health workers (CHWs) (overall: 10.7\%, small sites: $11.1 \%$, large sites: $10.5 \%$ ), and mental health providers (overall: $4.9 \%$, small sites: $4.2 \%$, large sites: 5.4\%). Patients of small CHC sites reported higher PACIC-11 scores (overall: 51.3, small sites: 53.5, large sites: $49.9, P=.02)$. Three out of 4 patients (75.0\%) had HbA1c under control and this did not differ between small and large CHC sites (small sites: $75.8 \%$ vs large sites: $74.6 \%$ ). 
Table 2. Descriptive Statistics for Care Team Expertise, Hemoglobin A1c Control, and Patients' Experiences of Chronic Care (PACIC-11) in the Overall Sample and Compared between Small and Large Community Health Center (CHC) Sites, 2011 to 2012

\begin{tabular}{|c|c|c|c|c|}
\hline $\begin{array}{l}\text { Variable } \\
\text { Percentage of Population, Mean (Standard Error) }\end{array}$ & Overall & Small CHC Site & Large CHC Site & $P$-Value \\
\hline Overall team expertise, count & $0.88(1.34)$ & $0.88(1.39)$ & $0.87(1.31)$ & .94 \\
\hline \multicolumn{5}{|l|}{ Interdisciplinary expertise on the primary care team, \% } \\
\hline Community health worker & $11.7 \%$ & $12.2 \%$ & $11.3 \%$ & .65 \\
\hline Diabetes educator & $21.0 \%$ & $22.1 \%$ & $20.3 \%$ & .44 \\
\hline Nutritionist & $30.9 \%$ & $30.4 \%$ & $31.1 \%$ & .77 \\
\hline Pharmacist & $19.8 \%$ & $21.1 \%$ & $19.0 \%$ & .38 \\
\hline Mental health provider & $5.2 \%$ & $4.5 \%$ & $5.7 \%$ & .38 \\
\hline Other staff & $24.3 \%$ & $28.7 \%$ & $21.6 \%$ & $.01^{*}$ \\
\hline Hemoglobin A1c control (<8.0\%) & $75.0 \%$ & $75.8 \%$ & $74.6 \%$ & .99 \\
\hline Patients' experiences of chronic care (PACIC-11) & 51.27 & 53.53 & 49.90 & $.02^{*}$ \\
\hline Observations & 1277 & 484 & 793 & \\
\hline
\end{tabular}

This comparison of means analyses utilizes $\chi^{2}$ tests for categorical variables and $t$-test for continuous variables to compare average values of main predictor variables for patients in small versus large community health center sites.

${ }^{*} P$-values represent the significance of differences in individual characteristics between small versus large $\mathrm{CHC}$ sites.

In adjusted analyses, patients with access to CHWs $(\beta=7.67, \quad P \leq .01)$, diabetes educators $(\beta=6.05, P \leq .01)$, nutritionists $(\beta=5.21, P \leq .01)$, and other general staff $(\beta=4.96, P=.02)$ had significantly higher PACIC-11 scores compared with patients without access to their expertise. Patients of small CHC sites who had broader overall team expertise reported better experiences of chronic care $(\beta=2.15, P=.03)$, but this relationship did not hold for patients of large CHC sites. The interaction between large $\mathrm{CHC}$ site size and broader care team expertise range is statistically significant, where patients of large CHC sites with broader team expertise had lower PACIC-11 scores $(\beta=-2.58, P=.01)$ (Figure 1). These PACIC-11 findings are consistent in a regression model that included IPTW to account for potential selection effects, except for the association of access to CHWs and general staff with higher PACIC-11 scores, which attenuated.

Overall interdisciplinary expertise on the primary care team, access to specific team expertise, $\mathrm{CHC}$ site size, and the interaction of overall access and $\mathrm{CHC}$ site size were not associated with odds of HbA1c control $(<8.0 \%)$ in adjusted analyses (Table 3). Chinese-speaking Asian patients (Odds Ratio $[\mathrm{OR}]=2.20, P<.01)$ and English-speaking patients of other racial/ethnic backgrounds $(\mathrm{OR}=$ 2.22, $P=.01)$ had significantly higher odds of HbA1c control than Spanish-speaking Latino patients. Patients between the ages of 36 and 45 years $(\mathrm{OR}=0.43, P<.01)$ and 46 to 55 years old $(\mathrm{OR}=0.58, P<.01)$ had significantly lower odds of HbA1c control compared with patients 56 to 65 years old. Estimating a logistic model with a control cut point of HbA1c $\leq 9.0 \%$ produced similar results, with minor deviations in coefficients and statistical significance levels for control variables (race/ethnicity/language and age), potentially due to different statistical power with less patients with glycemic control compared with the $\leq 8.0 \% \mathrm{HbA1}$ c cut point. Sensitivity analyses that estimated a linear regression model for a continuous specification of the HbA1c outcome and included IPTW to account for potential selection effects produced consistent results with the logistic regression and unweighted regression model specifications.

\section{Discussion}

Our findings indicate that patient access to specific interdisciplinary care team expertise is associated with better experiences of chronic care for adult $\mathrm{CHC}$ patients with diabetes. Namely, patient access to $\mathrm{CHWs}$, diabetes educators, nutritionists, and other general staff for diabetes care is associated with higher PACIC-11 scores. Interdisciplinary care team expertise, including $\mathrm{CHWs}$ and diabetes educators, have unique skills and experiences that 
Figure 1. Association of community health center (CHC) size and interdisciplinary care team expertise with patient assessment of chronic care, 2011 to 2012. Margin plots depict adjusted score for Patient Assessment of Chronic Illness Care (PACIC-11). Overall interdisciplinary primary care team expertise includes community health workers, diabetes educators, nutritionists, pharmacists, mental health providers, and other general staff. Small CHC sites have less than 250 adult patients with diabetes compared with large community health center sites with 250 or more adult patients with diabetes.

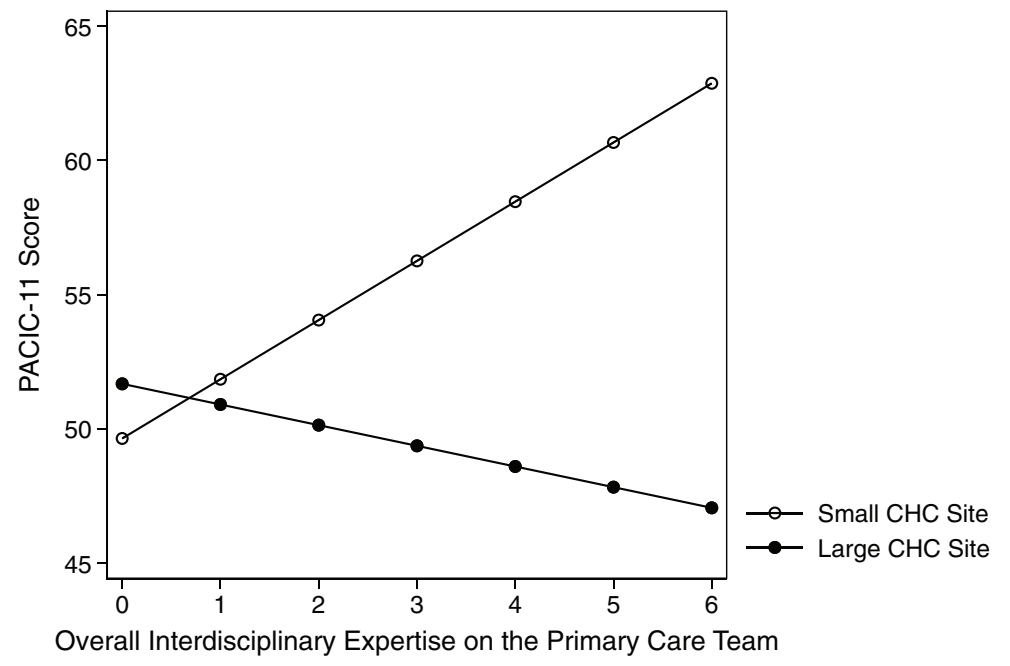

can aid diabetes self management for socioeconomically vulnerable patients, and our results provide evidence of their benefit in the patient experience. The benefit of empowering medical assistants to take more responsibility for patient care has been demonstrated in high-performing safety net clinics. ${ }^{36}$ Diabetes educators and nutritionists are also well positioned to provide selfmanagement support that can advance patient-centered chronic care. ${ }^{37-41}$

Despite their potential advantages, access to non-PCC expertise was low overall, with only $10 \%$ to $30 \%$ of adults with diabetes reporting $\mathrm{CHWs}$, diabetes educators, nutritionists, or other general staff as members of their care team. Patients of small and large CHCs sites have similar access to overall and specific interdisciplinary care team expertise, except patients of small CHC sites are more likely to report other general staff as care team members than patients at large $\mathrm{CHC}$ sites. Taken together, the results indicate that patients of small CHC sites do not necessarily have worse access to interdisciplinary care team expertise, potentially because $\mathrm{CHC}$ organizations and networks allow for small CHC sites to leverage centralized resources.

The relationship between broader primary care team expertise and better patients' experiences of chronic care, as measured by PACIC-11, was significant in small CHC sites but not large CHC sites. Patients of smaller primary care practices have fewer preventable hospital admissions ${ }^{15}$ and better access to care compared with patients of larger primary care practices. ${ }^{42}$ While smaller primary care practices have lower adoption of patient-centered medical home processes, ${ }^{43-46}$ they can prioritize reforms that leverage their interpersonal advantages, such as professional team training or expanding the role of medical assistants to improve patient self management. ${ }^{47,48}$ Physician retention has been found to be lower in CHC sites with lower visit volume, ${ }^{49}$ small CHC sites may be better positioned to foster patient relationships through team-based care because non-PCCs are more prepared to maintain relational continuity with patients due to high PCC turnover.

In adjusted analyses, broader interdisciplinary care team expertise was not associated with $\mathrm{HbA1c}$ control for either $8.0 \%$ or $9.0 \%$ cut points. Patients in the analytic sample had an average of 3 comorbid conditions. It is difficult to achieve HbAlc control when patients have multiple comorbidities, ${ }^{27,50}$ and broadening of primary care team expertise may have diminishing returns to patient self management, and consequently, $\mathrm{HbA1c}$ is not better for patients with access to broader team expertise. 
Table 3. Predictors of Odds of Hemoglobin A1c (HbA1c) and Patients' Experiences of Chronic Care (PACIC-11), 2011 to 2012

\begin{tabular}{|c|c|c|}
\hline & $\begin{array}{c}\text { Model 1: Odds } \\
\text { of HbAlc } \\
\text { Control }\end{array}$ & $\begin{array}{l}\text { Model 2: } \\
\text { PACIC-11 } \\
\text { Score }\end{array}$ \\
\hline Overall team expertise & $1.07(0.11)$ & $2.15^{*}(1.02)$ \\
\hline Large CHC site & $0.76(0.21)$ & $1.89(2.12)$ \\
\hline $\begin{array}{l}\text { Large CHC site \# overall } \\
\text { team expertise }\end{array}$ & $0.92(0.10)$ & $-2.58^{*}(1.04)$ \\
\hline \multicolumn{3}{|l|}{$\begin{array}{l}\text { Interdisciplinary expertise on } \\
\text { the primary care team: }\end{array}$} \\
\hline Community health worker & $0.93(0.26)$ & $7.67^{\dagger}(2.68)$ \\
\hline Diabetes educator & $0.69(0.15)$ & $6.05^{\dagger}(2.00)$ \\
\hline Nutritionist & $1.05(0.22)$ & $5.21^{\dagger}(1.98)$ \\
\hline Pharmacist & $0.84(0.19)$ & $-0.17(2.19)$ \\
\hline Mental health provider & $0.98(0.34)$ & $-0.42(3.29)$ \\
\hline Other staff & $1.11(0.24)$ & $4.96^{*}(2.03)$ \\
\hline Total comorbidities & $0.99(0.04)$ & $-0.03(0.39)$ \\
\hline Female & $1.26(0.20)$ & $-1.96(1.45)$ \\
\hline \multicolumn{3}{|l|}{ Race/ethnicity/language } \\
\hline Chinese-speaking Asian & $0.99(0.36)$ & $-5.37(2.89)$ \\
\hline English-speaking Asian & $0.58(0.22)$ & $10.73^{\dagger}(3.32)$ \\
\hline English-speaking Latino & $0.49^{*}(0.17)$ & $7.85^{\dagger}(3.00)$ \\
\hline Spanish-speaking Latino & $0.45^{*}(0.14)$ & $8.63^{\dagger}(2.74)$ \\
\hline English-speaking Other & Ref. & Ref. \\
\hline \multicolumn{3}{|l|}{ Insurance source } \\
\hline Medicaid & Ref. & Ref. \\
\hline Medicare & $1.44(0.58)$ & $0.48(3.34)$ \\
\hline Other & $0.70(0.34)$ & $3.62(4.73)$ \\
\hline Private & $1.21(0.29)$ & $-1.87(2.18)$ \\
\hline Uninsured & $1.30(0.31)$ & $-1.06(2.07)$ \\
\hline \multicolumn{3}{|l|}{ Age (years old) } \\
\hline 26 to 35 & $0.46(0.19)$ & $-0.36(4.20)$ \\
\hline 36 to 45 & $0.43^{\dagger}(0.11)$ & $2.61(2.54)$ \\
\hline 46 to 55 & $0.58^{\dagger}(0.11)$ & $-0.65(1.84)$ \\
\hline 56 to 65 & Ref. & Ref. \\
\hline 66 to 75 & $1.03(0.25)$ & $1.47(2.11)$ \\
\hline $76+$ & $1.29(0.44)$ & $-0.08(2.84)$ \\
\hline \multicolumn{3}{|l|}{ How long usual clinic (years) } \\
\hline$<3$ & Ref. & Ref. \\
\hline 3 to 5 & $1.22(0.24)$ & $2.63(1.78)$ \\
\hline $5+$ & $1.09(0.21)$ & $2.45(1.77)$ \\
\hline Constant & $0.88(0.36)$ & $50.97^{\ddagger}(3.13)$ \\
\hline$\Psi$ & $0.37(0.14)$ & $2.07(2.19)$ \\
\hline$\Theta$ & & $24.00(0.48)$ \\
\hline Observations & 1125 & 1277 \\
\hline
\end{tabular}

CHC, community health centers.

Standard errors in parentheses.

Model 1 displays odds ratio.

We were unable to assess 125 patients with no documentation of glycated hemoglobin (HbAlc) during the study period, leading to a Model 1 sub-sample of 1125.

${ }^{*} P<.05,{ }^{\dagger} P<.01,{ }^{\ddagger} P<.001$.
Our study also revealed important racial and ethnic disparities in diabetes care management. Spanishspeaking and English-speaking Latino patients were approximately half as likely to have controlled HbA1c than our reference group of English-speaking patients of other racial/ethnic backgrounds. These findings are consistent with evidence from a national study, which found that Latinos have worse HbA1c control than non-Latino white patients. ${ }^{51}$ Both English and Spanish-speaking Latinos were less likely to have HbA1c controlled compared with other racial/ethnic groups, consistent with evidence that Spanish language preference was not associated with better glycemic control among Latino patients. ${ }^{52}$ Latinos and English-speaking Asians had higher PACIC-11 scores than English-speaking patients of other racial/ethnic backgrounds. We are unable to assess why patients from certain racial and ethnic groups have different HbA1c control and experiences of chronic care, but previous analyses suggest factors we did not measure, including health literacy, ${ }^{53,54}$ geographic variation, ${ }^{55-57}$ and racial/ ethnic patient-clinician concordance, ${ }^{52,58}$ may account for differences. ${ }^{53}$ These factors should be assessed in future research to understand whether they explain racial and ethnic differences in diabetes care management.

Our results advance previous research in important ways. Research in commercially insured populations found overall care team expertise to be associated with better diabetes self-management support, but the effect of specific interdisciplinary expertise was not assessed. ${ }^{4}$ Our results extend evidence about the benefits of interdisciplinary care teams to CHCs, and our study includes care team members central to CHCs, including CHWs, diabetes educators, and general office staff such as medical assistants and clerks. The positive associations of access to $\mathrm{CHWs}$, diabetes educators, and general office staff on experience of chronic care for patients with diabetes is important because these team members are more common in safety net settings. These team members are more likely to come from similar socioeconomic and cultural backgrounds as patients, thereby reducing social distance and increasing connectedness, compared with PCC-only care. Medical assistants are one of the most diverse of all medical profession work forces and can serve as the "invisible glue" of primary care. ${ }^{47,48} \mathrm{CHW}$ are often "insiders" 
from the community that can create bridges to health care delivery. ${ }^{59}$ This study advances evidence about the benefits CHWs can have for diabetes care management for vulnerable populations. ${ }^{60-63}$ Our results suggest that patients may experience fewer communication and trust barriers when CHWs are involved as care team members, and their involvement on primary care teams may promote positive experiences of chronic care.

Implementing team-based care can be disruptive to operational workflows and requires flexibility to address the varying needs and resources of individual CHC sites. ${ }^{64-66}$ In resource-constrained CHCs, medical assistants are more likely than other staff to be pulled from their diabetes care management functions to support general operational tasks. ${ }^{34}$ While team-based care requires adaptation to fit local needs, practice-based research highlights that implementing effective interventions requires protected staff time for diabetes care management, warm hand-offs from PCCs to interdisciplinary team members, active support from site leadership, and standardized performance measurement across sites. $^{34,67-69}$ Teams will need to allocate tasks differently depending on available expertise..$^{70,71}$ For example, CHWs and medical assistants are both well positioned to support diabetes self management, and although they have different training, they can have fulfill common diabetes care management functions within and across $\mathrm{CHC}$ sites. ${ }^{27}$ Fidelity of implementation to interdisciplinary care team models has previously been associated with improved HbA1c control among adult patients with diabetes of a large medical group, but this relationship has yet to be assessed in CHCs. ${ }^{72}$ To advance research and practice, it will be important to clarify how the structural and relational features of primary care teams and fidelity of implementation can enable improved diabetes management for socioeconomically vulnerable patients. ${ }^{73}$

The study results should be considered in light of some limitations. First, we rely on patient reports of interdisciplinary expertise and cannot verify care team involvement. This study provides the opportunity to understand expertise that the patients directly identify as being involved in their chronic care. Doing so, however, may exclude "invisible" team members to patients, although patients' perspectives provide critical information about care teams. ${ }^{11}$ Second, "other staff" can include medical assistants, clerks, and other nonclinical staff, and we are unable to disentangle these roles. There is likely more overlap in the tasks performed by these staff members compared with clinicians, however, as they do not have strict licensing and training requirements. ${ }^{74-77}$ Third, we cannot assess causal relationships using crosssectional data and we are unable to rule out bias due to survey nonresponse. Nonresponse analyses indicate minor differences in age and race/ethnicity/language between respondents and nonrespondents (data not shown). To account for any differences, we include patient sex, age, race/ethnicity/language, insurance information, total comorbidities, and how long the site has been their usual clinic to help account for potential confounders. Further, we incorporate IPTW as a sensitivity analyses to account for potential selection bias. Finally, we are unable to assess how well non-PCC expertise is integrated into routine primary care. Information about team relational coordination and role clarity might elucidate the null $\mathrm{HbA1c}$ findings, as prior research highlights that factors beyond a care team's structure can impact patient outcomes. ${ }^{78-80}$

\section{Conclusion}

Over the past decade, CHCs have implemented diabetes self-management support, ${ }^{81,82}$ but team-based models have the potential to be expanded to better support socioeconomically vulnerable patients. Interdisciplinary primary care team development in $\mathrm{CHCs}$ is critical because of the challenges of recruitment, burnout, and turnover. ${ }^{6-8}$ Access to CHWs, diabetes educators, nutritionists, and other general staff support positive patients' experiences of chronic care. In small CHC sites, patients report better experiences of chronic care when they have broader access to expertise as well as access to specific interdisciplinary team members. Efforts to advance patient-centered care in $\mathrm{CHCs}$ should expand patient access to interdisciplinary expertise to support diabetes care management.

We thank Courtney Lyles, Stephen Shortell, and Amanda Brewster for helpful feedback on an earlier version of manuscript.

To see this article online, please go to: http://jabfm.org/content/ 34/1/151.full. 


\section{References}

1. Mensing C, Boucher J, Cypress M, et al. National standards for diabetes self-management education. Diabetes Care 2007;30:S96-S103.

2. Sarkar U, Fisher L, Schillinger D. Is self-efficacy associated with diabetes self-management across race/ethnicity and health literacy? Diabetes Care 2006;29:823-9.

3. Shetty G, Brownson CA. Characteristics of organizational resources and supports for self management in primary care. Diabetes Educ 2007;33:185S-192S. doi:10.1177/0145721707304171

4. Sequist TD, von Glahn T, Li A, Rogers WH, Safran DG. Statewide evaluation of measuring physician delivery of self-management support in chronic disease care. J Gen Intern Med 2009;24: 939-45.

5. Chin MH, Auerbach SB, Cook S, et al. Quality of diabetes care in community health centers. Am J Public Health 2000;90:431-4.

6. Chin MH, Cook S, Jin L, et al. Barriers to providing diabetes care in community health centers. Diabetes Care 2001;24:268-74.

7. Rosenblatt RA, Andrilla CHA, Curtin T, Hart LG. Shortages of medical personnel at community health centers: implications for planned expansion. JAMA 2006;295:1042-9.

8. Quinn MT, Gunter KE, Nocon RS, et al. Undergoing transformation to the patient centered medical home in safety net health centers: perspectives from the front lines. Ethn Dis 2013;23:356-62.

9. Kerse N, Buetow S, Mainous AG, Young G, Coster G, Arroll B. Physician-patient relationship and medication compliance: a primary care investigation. Ann Fam Med 2004;2:455-61.

10. Mainous AG, Baker R, Love MM, Gray DP, Gill JM. Continuity of care and trust in one's physician: evidence from primary care in the United States and the United Kingdom. Fam Med 2001;33:22-7.

11. Rodriguez HP, Rogers WH, Marshall RE, Safran DG. Multidisciplinary primary care teams: effects on the quality of clinician-patient interactions and organizational features of care. Med Care 2007;45:19-27.

12. Grace SM, Rich J, Chin W, Rodriguez HP. Implementing interdisciplinary teams does not necessarily improve primary care practice climate. Am J Med Qual 2016;31:5-11.

13. van den Hombergh $\mathrm{P}$, Engels $\mathrm{Y}$, van den Hoogen $\mathrm{H}$, van Doremalen J, van den Bosch W, Grol R. Saying 'goodbye'to single-handed practices; what do patients and staff lose or gain? Fam Pract 2005;22:20-7.

14. Abrams M, Schor EL, Schoenbaum S. How physician practices could share personnel and resources to support medical homes. Health Aff (Millwood) 2010;29:1194-9.
15. Casalino LP, Pesko MF, Ryan AM, et al. Small primary care physician practices have low rates of preventable hospital admissions. Health Aff (Millwood) 2014;33:1680-8.

16. $\mathrm{Ng}$ CWL, $\mathrm{Ng}$ KP. Does practice size matter? Review of effects on quality of care in primary care. Br J Gen Pract 2013;63:e604-e610.

17. Ong SE, Koh JJK, Toh SA, et al. Assessing the influence of health systems on type 2 diabetes mellitus awareness, treatment, adherence, and control: a systematic review. PloS One 2018;13:e0195086

18. Ruggiero L, Castillo A, Quinn L, Hochwert M. Translation of the diabetes prevention program's lifestyle intervention: role of community health workers. Curr Diab Rep 2012;12:127-37.

19. Powers MA, Bardsley J, Cypress M, et al. Diabetes self-management education and support in type 2 diabetes: a joint position statement of the American Diabetes Association, the American Association of Diabetes Educators, and the Academy of Nutrition and Dietetics. Diabetes Educ 2017;43:40-53.

20. Early KB, Stanley K. Position of the Academy of Nutrition and Dietetics: the role of medical nutrition therapy and registered dietitian nutritionists in the prevention and treatment of prediabetes and type 2 diabetes. J Acad Nutr Diet 2018;118:343-53.

21. Coast-Senior EA, Kroner BA, Kelley CL, Trilli LE. Management of patients with type 2 diabetes by pharmacists in primary care clinics. Ann Pharmacother 1998;32:636-41.

22. Young-Hyman D, De Groot M, Hill-Briggs F, Gonzalez JS, Hood K, Peyrot M. Psychosocial care for people with diabetes: a position statement of the American Diabetes Association. Diabetes Care 2016;39:2126-40.

23. Wetmore S, Boisvert L, Graham E, et al. Patient satisfaction with access and continuity of care in a multidisciplinary academic family medicine clinic. Can Fam Physician 2014;60:e230-e236.

24. Kaferle JE, Wimsatt LA. A team-based approach to providing asthma action plans. J Am Board Fam Med 2012;25:247-9.

25. Tapp H, Phillips SE, Waxman D, Alexander M, Brown R, Hall M. Multidisciplinary team approach to improved chronic care management for diabetic patients in an urban safety net ambulatory care clinic. J Am Board Fam Med 2012;25:245-6.

26. Margolius D, Wong J, Goldman ML, RouseIniguez J, Bodenheimer T. Delegating responsibility from clinicians to nonprofessional personnel: the example of hypertension control. J Am Board Fam Med 2012;25:209-15.

27. Rodriguez HP, Friedberg MW, Vargas-Bustamante A, Chen X, Martinez AE, Roby DH. The impact of integrating medical assistants and community health workers on diabetes care management in community health centers. BMC Health Serv Res 2018;18:875. doi:10.1186/s12913-018-3710-9. 
28. Nichols GA, Desai J, Elston Lafata J, et al. Construction of a multisite DataLink using electronic health records for the identification, surveillance, prevention, and management of diabetes mellitus: the SUPREME-DM project. Prev Chronic Dis 2012; 9:E110.

29. Gugiu PC, Coryn C, Clark R, Kuehn A. Development and evaluation of the short version of the Patient Assessment of Chronic Illness Care instrument. Chronic Illn 2009;5:268-76.

30. Glasgow RE, Wagner EH, Schaefer J, Mahoney LD, Reid RJ, Greene SM. Development and validation of the Patient Assessment of Chronic Illness Care (PACIC). Med Care 2005;43:436-44.

31. Bernstein IH, Nunnally J, Oliva TA, Oliver RL, MacMillan IC, A catastrophe model for developing service satisfaction strategies. J Marketing 1992;56: 83-95.

32. Bustamante AV, Martinez A, Chen X, Rodriguez HP. Clinic workload, the quality of staff relationships and diabetes management in community health centers catering to Latino and Chinese patients. J Commun Health 2017;42:481-8.

33. American Diabetes Association. 12. Older adults: standards of medical care in diabetes-2019. Diabetes Care 2019;42:S139-S147.

34. Van der Wees PJ, Friedberg MW, Guzman EA, Ayanian JZ, Rodriguez HP. Comparing the implementation of team approaches for improving diabetes care in community health centers. BMC Health Serv Res 2014;14:608.

35. Li C. Little's test of missing completely at random. STATA J 2013;13:795-809.

36. Lyson HC, Ackerman S, Lyles C, et al. Redesigning primary care in the safety net: a qualitative analysis of team-based care implementation. Healthc (Amst) 2019;7:22-9.

37. Mercurio A. The evolving role of health educators in advancing patient safety: forging partnerships and leading change. Health Promot Pract 2007;8: 119-27.

38. Holtrop JS, Jordan TR. The patient-centered medical home and why it matters to health educators. Health Promot Pract 2010;11:622-8.

39. Donnelly MB, Anderson RM. The role related attitudes of physicians, nurses, and dieticians in the treatment of diabetes. Med Care 1990;28: 175-9.

40. Clark M, Hampson SE. Comparison of patients' and healthcare professionals' beliefs about and attitudes towards type 2 diabetes. Diabet Med 2003; 20:152-4.

41. Siminerio LM. Deploying the chronic care model to implement and sustain diabetes self-management training programs. Diabetes Educ 2006;32:253-60.

42. Kontopantelis E, Roland M, Reeves D. Patient experience of access to primary care: identification of predictors in a national patient survey. BMC Fam Pract 2010;11:61.

43. Friedberg MW, Safran DG, Coltin KL, Dresser M, Schneider EC. Readiness for the patient-centered medical home: structural capabilities of Massachusetts primary care practices. J Gen Intern Med 2009; 24:162-9.

44. Wiley JA, Rittenhouse DR, Shortell SM, et al. Managing chronic illness: physician practices increased the use of care management and medical home processes. Health Aff (Millwood) 2015;34:78-86.

45. Rodriguez HP, McClellan SR, Bibi S, Casalino LP, Ramsay PP, Shortell SM. Increased use of care management processes and expanded health information technology functions by practice ownership and Medicaid revenue. Med Care Res Rev 2016; 73:308-28.

46. Rittenhouse DR, Casalino LP, Shortell SM, et al. Small and medium-size physician practices use few patient-centered medical home processes. Health Aff (Millwood) 2011;30:1575-84.

47. Chapman S, Marks A, Chan M. The Increasing role of medical assistants in small primary care physician practice: key issues and policy implications. 2010. Available from: https://healthforce.ucsf.edu/sites/ healthforce.ucsf.edu/files/publication-pdf/2.\%20201002_The_Increasing_Role_of_Medical_Assistants_ in_Small_Primary_Care_Physician_Practice.pdf.

48. Taché S, Hill-Sakurai L. Medical assistants: the invisible "glue" of primary health care practices in the United States? J Health Org Mgt 2010;24:288-305.

49. Singer JD, Davidson SM, Graham S, Davidson HS. Physician retention in community and migrant health centers: who stays and for how long? Med Care 1998;36:1198-213.

50. Vo MT, Uratsu CS, Estacio KR, et al. Prompting patients with poorly controlled diabetes to identify visit priorities before primary care visits: a pragmatic cluster randomized trial. J Gen Intern Med 2019;34:831-8.

51. Saydah S, Cowie C, Eberhardt MS, De Rekeneire N, Narayan KMV. Race and ethnic differences in glycemic control among adults with diagnosed diabetes in the United States. Ethn Dis 2007;17:529-35.

52. Lasater LM, Davidson AJ, Steiner JF, Mehler PS. Glycemic control in English- vs Spanish-speaking Hispanic patients with type 2 diabetes mellitus. Arch Intern Med 2001;161:77-82.

53. Leung LB, Vargas-Bustamante A, Martinez AE, Chen X, Rodriguez HP. Disparities in diabetes care quality by english language preference in community health centers. Health Serv Res 2018;53:509-31.

54. Hahn EA, Burns JL, Jacobs EA, et al. Health literacy and patient-reported outcomes: a cross-sectional study of underserved English- and Spanishspeaking patients with type 2 diabetes. J Health Commun 2015;20:4-15. 
55. Bynum JPW, Fisher ES, Song Y, Skinner J, Chandra A. Measuring racial disparities in the quality of ambulatory diabetes care. Med Care 2010;48:1057-63.

56. Baicker K, Chandra A, Skinner JS, Wennberg JE. Who you are and where you live: how race and geography affect the treatment of Medicare beneficiaries. Health Aff (Millwood) 2004;Suppl Variation: VAR33-VAR44.

57. Baicker K, Chandra A, Skinner J. Geographic variation in health care and the problem of measuring racial disparities. Perspect Biol Med 2005;48:42-S53.

58. Saha S, Komaromy M, Koepsell TD, Bindman AB. Patient-physician racial concordance and the perceived quality and use of health care. Arch Intern Med 1999;159:997-1004.

59. Love MB, Gardner K, Legion V. Community health workers: who they are and what they do. Health Educ Behav 1997;24:510-22.

60. Trinh-Shevrin C, Taher M, Islam N. Community health workers as accelerators of community engagement and structural competency in health. In: Hansen H, Metzl JM, eds. Structural competency in mental health and medicine: a case-based approach to treating the social determinants of health. New York, NY: Springer International Publishing; 2019; 167-77.

61. Kangovi S, Mitra N, Norton L, et al. Effect of community health worker support on clinical outcomes of low-income patients across primary care facilities: a randomized clinical trial. JAMA Intern Med 2018;178:1635-43.

62. Kangovi S, Mitra N, Grande D, Huo H, Smith RA, Long JA. Community health worker support for disadvantaged patients with multiple chronic diseases: a randomized clinical trial. Am J Public Health 2017;107:1660-7.

63. Vasan A, Morgan JW, Mitra N, et al. Effects of a standardized community health worker intervention on hospitalization among disadvantaged patients with multiple chronic conditions: a pooled analysis of three clinical trials. Health Serv Res 2020;55:894-901.

64. Nutting PA, Crabtree BF, Miller WL, Stewart EE, Stange KC, Jaen CR. Journey to the patient-centered medical home: a qualitative analysis of the experiences of practices in the national demonstration project. Ann Fam Med 2010;8:S45-S56.

65. Crabtree BF, Nutting PA, Miller WL, et al. Primary care practice transformation is hard work. Med Care 2011;49:S28-S35.

66. Wagner EH, Coleman K, Reid RJ, Phillips K, Abrams MK, Sugarman JR. The changes involved in patient-centered medical home transformation. Prim Care 2012;39:241-59.

67. Grace SM, Rich J, Chin W, Rodriguez HP. Flexible implementation and integration of new team members to support patient-centered care. Healthc (Amst) 2014;2:145-51.
68. Bodenheimer T, Ghorob A, Willard-Grace R, Grumbach K. The 10 building blocks of high-performing primary care. Ann Fam Med 2014;12: 166-71.

69. Ngo V, Hammer H, Bodenheimer T. Health coaching in the Teamlet model: a case study. J Gen Intern Med 2010;25:1375-8.

70. Donelan K, Chang Y, Berrett-Abebe J, et al. Care management for older adults: the roles of nurses, social workers, and physicians. Health Aff (Millwood) 2019;38:941-9.

71. Berrett-Abebe J, Donelan K, Berkman B, Auerbach D, Maramaldi P. Physician and nurse practitioner perceptions of social worker and community health worker roles in primary care practices caring for frail elders: Insights for social work. Soc Work Health Care 2020;59:46-60.

72. Grace SM, Rich J, Chin W, Rodriguez HP. Fidelity of implementation to a care team redesign and improved outcomes of diabetes care. Int J Qual Health Care 2015;27:60-6.

73. Fixsen DL, Blase KA, Naoom SF, Wallace F. Core implementation components. Res Soc Work Pract 2009;19:531-40.

74. Skillman SM, Dahal A, Frogner BK, Andrilla CHA. Frontline workers' career pathways: a detailed look at Washington state's medical assistant workforce. Med Care Res Rev 2020;77:285-93.

75. Tache S, Chapman S. What a medical assistant can do for your practice. FPM 2005;12:51.

76. Chapman SA, Blash LK. New roles for medical assistants in innovative primary care practices. Health Serv Res 2017;52:383-406.

77. MacKay FD, Anderson JE, Klein MC. The modified medical office assistant role in rural diabetes care. Can J Rural Med 2014;19:49-56.

78. Strasser DC, Falconer JA, Herrin JS, Bowen SE, Stevens AB, Uomoto J. Team functioning and patient outcomes in stroke rehabilitation. Arch Phys Med Rehabil 2005;86:403-9.

79. Propp KM, Apker J, Zabava Ford WS, Wallace N, Serbenski M, Hofmeister N. Meeting the complex needs of the health care team: identification of nurseTeam communication practices perceived to enhance patient outcomes. Qual Health Res 2010;20:15-28.

80. Grumbach K, Bodenheimer T. Can health care teams improve primary care practice? JAMA 2004;291:1246-51.

81. Sugarman JR, Phillips KE, Wagner EH, Coleman $\mathrm{K}$, Abrams MK. The safety net medical home initiative: transforming care for vulnerable populations. Med Care 2014;52:S1-S10.

82. Wagner EH, Gupta R, Coleman K. Practice transformation in the safety net medical home initiative: a qualitative look. Med Care 2014;52:S18-S22. 